Disclosure of Interest: I. Castrejon: None declared, K. Gibson: None declared, J. Block: None declared, T. Pincus Shareholder of: Health Report Services, Inc DOI: 10.1136/annrheumdis-2017-eular.5209

\section{THU0473 POLYSYMPTOMATIC DISTRESS SCALE, WIDE SPREAD PAIN INDEX, AND SYMPTOM SEVERITY SCALES, AND THEIR CORRELATES IN 169 PATIENTS WITH FIBROMYALGIA SYNDROME}

K. Yaseen ${ }^{1}$, S. Kaouk ${ }^{2}$, D. Bork ${ }^{3}$, W.S. Wilke ${ }^{3}$, C. Gota ${ }^{3} .{ }^{1}$ Internal Medicine, Cleveland Clinic; ${ }^{2}$ Rheumatology, John Carroll University; ${ }^{3}$ Rheumatology, Cleveland Clinic, Cleveland, United States

Background: The polysymptomatic distress scale (PSD) is considered a measure of FM severity and ranges from 0 to 31 . It is calculated by adding the two components of the American College of Rheumatology (ACR) 2010 fibromyalgia (FM) criteria, widespread pain index (WPI) and symptoms severity scale (SS).

Objectives: Determine the relationship between depression, anxiety, function disability and pain related disability, with fibromyalgia severity as measured by PSD and its subsets, WPI and SS.

Methods: All consecutive FM patients who met the ACR 2010 criteria completed the following questionnaires: $\mathrm{PSD}$, patient health related questionnaire (PHQ-9), a measure of depressive symptoms, general anxiety disorder questionnaire (GAD-7), health assessment questionnaire disability index (HAQ-DI), and pain disability index (PDI).

Results: Of 169 patients, 85.7\% were women, mean age 42.3 (13.3), BMI 29.3 (7.1), PHQ-9 13.7 (5.2), GAD-7 10.2 (9.1), HAQ-DI 1.6 (2.9), PDI 6 (2.1), WPI 14.3 (2.7), SS 10 (1.6). In univariate analysis PSD correlated significantly $(p<0.01)$ with PHQ-9 (0.576), PDI (0.422), and GAD-7 (0.356). Widespread pain index correlated significantly with PHQ-9 (0.313), GAD-7 (0.239), HAQ-DI (0.259), and PDI (0.296). Symptom severity scale correlated significantly with PHQ-9 (0.496), GAD-7 (0.337), HAQ-DI (0.275), PDI (0.340). A linear regression analysis model, which included PHQ-9, GAD-7, PDI and HAQ-DI predicted 0.269 of $P S D$ variance, $p=0.001$, and only $P D I$ remained significantly correlated with PSD. A similar model predicted 0.348 of SS variance, $(P<0.0001)$, and only PHQ-9 remained significantly correlated with SS. This model did not significantly predict WPI variability.

Conclusions: Depression, anxiety, pain disability and functional disability predict a small variance of fibromyalgia severity measured by PSD. In regression analysis, pain disability measured by PDI is the only variable that remains independently correlated with PSD. None of these variables predicted WPI, while depression measured by PHQ-9 remains independently correlated with SS, indicating that PSD subsets measure different dimensions of FM.

Disclosure of Interest: None declared

DOI: 10.1136/annrheumdis-2017-eular.4343

\section{THU0474 A CROSS-SECTIONAL STUDY INTO THE EFFECTIVENESS OF THE FIBROMYALGIA RAPID SCREENING TOOL FOR DETECTING FM IN PATIENTS WITH CHRONIC ARTHRITIS UNDERGOING FULL AND TAPERED BIOLOGICAL DISEASE-MODIFYING ANTIRHEUMATIC DRUG THERAPY}

L. Valor, D. Hernández Flórez, T. del Río, I. Janta, J. Martínez Barrio, J.G. Ovalles B., B. Serrano, R. González Benítez, C. Sáenz Tenorio, J.C. Nieto, C. González, I. Monteagudo, F.J. López-Longo. Rheumatology, Hospital General Universitario Gregorio Marañón, Madrid, Spain

Background: The determination of fibromylagia (FM) in patients presenting diffuse, chronic arthritis is fraught. The Fibromyalgia Rapid Screening Tool (FiRST) is a validated questionnaire with high sensitivity and moderate specificity shown to be able to identify up to $89 \%$ of FM cases, even when accompanied by anxiety, depression or functional disability. Decisions to embark upon a course of full or tapered biological disease-modifying antirheumatic drugs (bDMARD) are influenced in part by patient self-assessment scores as well as concomitant pathologies.

Objectives: To evaluate the prevalence of FM using the FiRST questionnaire in bDMARD-treated chronic arthritis patients.

Methods: This cross-sectional study included 325 patients [178 $(54,8 \%)$ females and $147(45,2 \%)$ males] diagnosed with chronic arthritis and treated with bDMARD. Patients were consecutively recruited from the Biological Therapy Unit from January to March 2015 all having undergone full or tapered bDMARD for at least 1 year. Dosage tapering had been applied to patients considered to be in remission. All patients self-completed the FiRST questionnaire with a score $>5 / 6$ considered positive. Clinical assessment was carried out by one specialist only. Demographic, clinical and laboratory variables were recorded with pathologyspecific indices used to assess disease status, i.e.DAS28-ESR, DAS28-CRP, SDAI, CDAI, BASDAI, BASFI, ASDAS-CRP. Patient pathologies were classified as peripheral arthritis (PerAR: RA, PsA, PerSpA) or axial spondyloarthropathy type (AxSpA)

Results: A total of $68 / 325(21 \%)$ patients scored $>5 / 6$ in the FiRST. Disease duration and previous bDMARD usage were not significant regarding scores $<5 / 6$. In the PerAR vs. AxSpA group, we observed that $19 \%(n=43)$ and $35 \%(n=25)$ scored FiRST $>5 / 6$, respectively $(p=N S)$. Fifteen per cent of patients with tapered
bDMARD registered scores $>5 / 6$ against $85 \%$ of patients in full bDMARD dosage $(p=0.001)$. There were a higher number of remission patients in the PerAR group as defined under DAS28-ESR, SDAI and CDAI [(96\%, 94\% and 94\%) $(p=0.01$, $\mathrm{p}=0.04, \mathrm{p}=0.032$ ), respectively]. Association was found in the PerAR subgroups between tapered bDMARD and remission in RA patients only, as defined under DAS28-VSG, SDAI and CDAI ( $p=0.026, p=0.04, p=0.043$, respectively). In the AxSpA tapered bDMARD subset, $86 \%$ of patients were considered to be in clinical remission as set out under BASDAI $(p=0.019)$.

Conclusions: No difference was observed between the PerAR and AxSpA groups for FiRST>5/6. Fewer patients undergoing tapered bDMARD dosage recorded FiRST scores $>5 / 6$. Therefore, early identification of chronic arthritic patients presenting FiRST $>5 / 6$ may prove to be an important step in furthering understanding of clinical activity in diffuse arthritis as well as offering improved diagnostic and therapeutic outcomes to bDMARD-treated patients with possible concomitant FM.

Disclosure of Interest: None declared

DOI: 10.1136/annrheumdis-2017-eular.4768

\section{THU0475 EVALUATION OF PELVIC FLOOR STRENGTH AND URINARY INCONTINENCE IN WOMEN WITH FIBROMYALGIA}

M.A.G. Pontes Filho ${ }^{1}$, H.C.S.C. Fusco ${ }^{2}$, E.A.G. Ferreira ${ }^{2}$, A.P. Marques ${ }^{2}$. $^{2}$

${ }^{1}$ Reumatologia, Hospital das Clínicas da Faculdade de Medicina da Universidade de São Paulo; '2Fisioterapia, Fonaudiologia e Terapia Ocupacional, Universidade de São Paulo, Sao Paulo, Brazil

Background: Fibromyalgia (FM) is characterized by the American College of Rheumatology as chronic widespread pain referred for at least 3 months. In 2010 , a new diagnostic criteria was proposed and includes symptoms such as fatigue, sleep disorder and memory. Currently, pelvic floor dysfunctions and urinary incontinence (UI) are considered public health problems with high prevalence and great impact on quality of life (QoL) and on women's self-esteem. Physiotherapists have been working to create a new treatment proposal that can cover all aspects of FM, however there are few studies that include pelvic floor evaluation and urinary continence of this population.

Objectives: To assess the strength of the pelvic floor and urinary loss in women with FM.

Methods: We evaluated 126 sexually active women, aged between 19 and 65 years, with and without medical diagnosis of FM, matched for age and menopausal status, in a single center. The exclusion criteria were sexually transmitted or neurological diseases, pregnancy and use of medications with urinary side effects (urinary loss or retention). We collected in a single interview personal and gynecological data, applied the King Health Questionnaire (KHQ) for incontinent women and accomplished the evaluation of pelvic floor muscle strength according to the Oxford Classification Modified and perineometry. The participants signed the Informed Consent Form. We used for statistical analysis t test for independent variables and Mann-Whitney Test for the others.

Results: The FM patients presented the weaker pelvic floor $(p<0.001)$ and had lower values in perineometry $(p=0.04)$ than control women. Regarding urinary loss, $64.5 \%$ reported $\mathrm{UI}$ against $26.6 \%$ of women without FM. In the $\mathrm{KHQ}$ evaluation, in General Health and Emotions domains, women with FM presented worse performance $(p<0.001$ and $p=0.046$, respectively).

Conclusions: Urinary incontinence is a frequent finding in FM, and it could be related to the degree of strength of the pelvic floor muscles. This condition affects negatively QoL, especially with regard to emotions and general health.

References:

[1] Wolfe, et al. The American College of Rheumatology Preliminary Diagnistic Criteria for Fibromyalgia and Measurement of Symptom Severity. Arthritis Care \& Research, v.2, n.5, pg. 600-610, 2010.

[2] Jones, K. D. et al. Pelvic Floor and Urinary Distress in Women with Fibromyalgia. Pain Management Nursing, v. 16, n. 6, p. 834-840, Dec 2015. Acknowledgements: This study received funds from CAPES (Coordination for the Improvement of Higher Education Personnel - Government Research Agency) with scholarship to one of the co-authors.

Disclosure of Interest: None declared

DOI: 10.1136/annrheumdis-2017-eular.6261

\section{THU0476 EVALUATION OF SEXUAL FUNCTION IN WOMEN WITH FIBROMYALGIA}

M.A.G. Pontes Filho ${ }^{1}$, H.C.S.D.C. Fusco ${ }^{2}$, R.T. Cônsolo ${ }^{2}$, E.A.G. Ferreira ${ }^{2}$ ${ }^{1}$ Reumatologia, Hospital das Clínicas da Faculdade de Medicina da Universidade de São Paulo; ${ }^{2}$ Fisioterapia, Fonaudiologia e Terapia Ocupacional, Universidade de São Paulo, Sao Paulo, Brazil

Background: Fibromyalgia (FM) is defined by the American College of Rheumatology as a syndrome of unknown etiology, characterized by chronic and widespread musculoskeletal pain. In 2010, a new diagnostic criteria was proposed and involves not only pain but symptoms such as depression, muscle fatigue, non-restorative sleep and urinary disorders. This may lead to a lack of interest or difficulty in the sexual act, which tends to be aggravated by depression, which is manifested by low self-esteem, decreased desire and orgasm, and pain during sexual intercourse. 
Objectives: Compare the sexual function of women with and without FM.

Methods: Sexually active women aged between 19 and 65 years with and without medical diagnosis of FM in a single center, matched for age and menopausal status, were evaluated. The exclusion criteria were pregnancy and use of medications with urinary side effects (urinary loss or retention). In a single interview the participants signed the Informed Consent Form and answered questions about personal and gynecological data. The protocol The Sexual Quotient - Female Version (QS-F) was applied to assess sexual performance. We used for statistical analysis $t$ test for independent variables and Mann-Whitney Test for the others.

Results: In this study, 126 women were evaluated with age of $43.73 \pm 10.48$ years. Most of the patients were married, representing $58.7 \%$. A total of $50 \%$ participants had 1 or 2 children, $22.2 \%$ between 3 and 4 children and $27.8 \%$ had no children. Regarding the age of menarche and manopausal status, no differences were observed between groups ( $p=0.70$ and $p=0.08$, respectively). The QS-F score revealed significantly lower scores for women with FM when compared to the healthy group $(p<0.001)$. We observed the same results in the domains: Desire and Sexual Interest $(\mathrm{p}<0.001)$, Excitation Phase $(\mathrm{p}=0.019)$ and Satisfaction and Orgasm $(p<0.001)$. Regarding the Pain and Comfort domain, no differences were observed between the groups $(p=0.307)$. However, when they were questioned about dyspareunia in the physiotherapeutic evaluation, it was observed that $51.6 \%$ of FM patients reported pain in sexual act against only $26.6 \%$ of healthy women $(p=0.005)$.

Conclusions: Women with FM performed poorly on QS-F general score and in most domains, except for pain and comfort. When they were questioned in the physiotherapeutic evaluation about dyspareunia, we observed that women with FM had more pain in sexual intercourse, which may occurred due to the way the question was asked. As consequence, women with FM report worse sexual performance, especially with regard to desire, arousal phase and orgasm rate.

\section{References:}

[1] Wolfe, et al. The American College of Rheumatology Preliminary Diagnistic Criteria for Fibromyalgia and Measurement of Symptom Severity. Arthritis Care \& Research, v.2, n.5, pg. 600-610, 2010.

[2] Rebecca G. Rogers, M.D. Sexual function in women with pelvic floor desorders.

Can Urol Assoc J.; v 7, n. 9-10, p. 199-201, 2013.

Acknowledgements: This study received funds from CAPES (Coordination for the Improvement of Higher Education Personnel - Government Research Agency) with scholarship to one of the co-authors.

Disclosure of Interest: None declared

DOI: 10.1136/annrheumdis-2017-eular.6293

\section{THU0477 DOES FIBROMYALGIA AFFECT PHYSICAL ACTIVITY OF THE PATIENTS?}

M. Alkan Melikoglu ${ }^{1}$, S. Dogantekin ${ }^{2} .{ }^{1}$ Rheumatology, ATATURK UNIVERSITY FACULTY of MEDICINE, Rheumatology; ${ }^{2}$ Physical medicine and Rehabilitation, ATATURK UNIVERSITY FACULTY of MEDICINE, Erzurum, Turkey

Background: Fibromyalgia syndrome (FMS) as a chronic pain condition can cause impaired physical activity level of the patients.

Objectives: The purpose this case-control study was to evaluate the physical activity levels of patients with FMS and to assess a possible relation between physical activity and disease characteristics.

Methods: Seventy patients with FMS and 50 age-gender matched controls were included in the study. The demographic features and duration of symptoms of the participants were recorded. The level of pain was evaluated using the visual analogue scale (VAS). The Fibromyalgia Impact Questionnaire (FIQ) scoring system was used for the evaluation of the impact of FMS. Also for assessing the physical activity in our participants, we used The International Physical Activity Questionnaire (IPAQ). Mann-Whitney U and Pearson correlation tests were used for group comparisons and was used for correlation analyses.

Results: The mean age of the patients and healthy controls were $41,90 \pm 8,53$ years and $41,52 \pm 9,01$ years, respectively. Symptom duration of the patients was $61,0 \pm 45,8$ months. The patients with FMS presented significantly less transportation-related, recreational and total physical activity levels, besides reporting significantly less time spent walking and less time spent in vigorous activities than healthy controls $(\mathbf{p}<0,05)$. Also, in patients with FMS, there was a negative correlation between pain and the scores of self-reported moderate or vigorous physical activity $(r=-0.41, p<0.01)$. However, we couldn't find any correlation between FIQ and IPAQ scores.

Conclusions: Patients with FMS are physically less active than healthy individuals of similar profile. This reduced activity seems to be associated with pain, but not with the impact of the disorder. In the approach to the patient with FMS, considering the patient's physical activity behavior can contribute to the management of the disorder. In future studies assessing the effect of exercise in FMS, consideration of the patients' physical activity level may contribute to a complete evaluation of the patients.

Disclosure of Interest: None declared

DOI: 10.1136/annrheumdis-2017-eular.3092

\section{THU0478 DETERMINATION OF COMORBIDITIES IN FIBROMYALGIA SYNDROME}

U. Bilge ${ }^{1}$, T. Kaşifoğlu ${ }^{2}$, N.S. Yașar Bilge ${ }^{2}$, H. Balcıoğlu ${ }^{1}$, Y.E. Sarı ${ }^{1}$, M. Kayhan ${ }^{1}$, I. Ünlüoğlu ${ }^{1} .{ }^{1}$ Eskişehir Osmangazi University Faculty of Medicine Department of Family Medicine, Eskişehir Osmangazi University Faculty of Medicine Department of Family Medicine; ' ${ }^{2}$ Eskişehir Osmangazi University, Eskişehir Osmangazi University Faculty of Medicine Department of Internal Medicine Division of Rheumatology, Eskişehir, Turkey

Background: Although fibromyalgia syndrome is diagnosed by excluding other possible diagnosis based on the patient's clinical features, in recent the studies, it was shown that comorbid diseases affect the course of fibromyalgia.

Objectives: The aim of this study is to evaluate the comorbid diseases of patients with fibromyalgia and to determine the rates of comorbid diseases

Methods: In this study, age, gender and comorbid diseases of patients above 18 years and diagnosed with fibromyalgia by a were evaluated in the database system of the hospital retrospectively.

Results: A total of 509 patients were examined in our study. 51 of the patients were male, 458 were female (mean age was $50.24 \pm 12.32$ ). Of the patients, 345 $(67.8 \%)$ had at least one comorbid disease while $164(32.2 \%)$ had no comorbid disease. In the study, 187 of the patients $(36.7 \%)$ had cardiovascular diseases, 157 of the patients $(30.8 \%)$ had endocrine diseases, 63 of the patients $(12.4 \%)$ had rheumatologic diseases, 30 of the patients $(5.9 \%)$ had neurological diseases, 14 of the patients $(2.8 \%)$ had other autoimmune diseases, 10 of the patients $(2.0 \%)$ had cancers, 129 of the patients $(25.3 \%)$ had mental disorders, 45 of the patients $(8.8 \%)$ had chronic lung diseases, 37 of the patients $(7.3 \%)$ had osteoporosis, 11 of the patients $(2.2 \%)$ had other diseases (chronic pancreatitis, chronic renal failure, nephrotic syndrome, deep vein thrombosis, hepatitis serology positivity, pulmonary thromboembolism, organ transplantation).

Conclusions: FMS is an important disease that is increasing in frequency in recent years. FMS, which can be seen with many diseases, is in fact related to physicians from many branches, and it is useful to evaluate FMS patients with their comorbid conditions on their follow-up.

References:

[1] Choy EH \& Mease PJ. Key symptom domains to be assessed in fibromyalgia (outcome measures in rheumatoid arthritis clinical trials). Rheumatic Disease Clinics of North America, 2009; 35(2):329-337.

[2] Wolfe F, Smythe HA, Yunus MB, Bennett RM, Bombardier C, Goldenberg $\mathrm{DL}$, et al. The American College of Rheumatology 1990 criteria for the classification of fibromyalgia. Arthritis \& Rheumatism, 1990; 33(2):160-172.

[3] Soran N, Altındağ Ö, Demirkol A, Sallı A, Yılmaz $H$, Kocabas $H$, et al. Depression level and relation with clinical parameters in fibromyalgia syndrome. Rheumatism, 2008; 23:1-4.

Disclosure of Interest: None declared

DOI: 10.1136/annrheumdis-2017-eular.5877

\section{THU0479 THE PREVALENCE OF XEROSTOMIA IN PATIENS WITH FIBROMYALGIA}

N.M. Lloves Schenone, A. Secco, V. Durigan, S. Scarafia, F.E. Romanini, M. Mamani. Servicio de Reumatología, Hospital Bernardino Rivadaiva, Buenos Aires, Argentina

Background: Fibromyalgia (FM) is a rheumatic disease characterized by diffuse, chronic musculoskeletal pain, of non-articular origin, which is evidenced by the palpation of painful points in specific anatomical areas and is usually accompanied by non-repairing sleep, Tiredness, morning stiffness, cognitive alterations, among others.

FM affects approximately $0.5-5 \%$ of the population, having a maximum prevalence between 40 and 50 years. No racial or socioeconomic predisposition has been determined to date.

Sicca syndrome whose term encompasses xerophthalmia, xerostomia, xeroderma and xerovagina, has been described in patients with FM. Xerostomia is the sensation of dry mouth due to lack or decrease of saliva. There are no clinical studies that determine the prevalence of xerostomia in patients with FM and on the other hand the reduction of salivary flow in these patients has not been studied with objective tests.

Objectives: The aim of this study was to determinate the frecuency of xerostomia in patients with diagnosis of Fibromyalgia and describe their clinical and epidemiologic characteristics.

Methods: Patients were included according 1990 and 2010 ACR Classification criteria. Patients taking drugs that cause xerostomia were excluded as well as the ones presenting other rheumatologic diseases. Xerostomia was assessed by interrogation and physical examination, and a sialometry was performed in order to determinate the decrease of salival flow. A sialometry was positive if the saliva flow was under $1.5 \mathrm{ml}$ in 15 minutes. In case of presenting positive sialometry patients were studied to rule out Sjogren Syndrome with laboratory and minor salivary gland biopsy.

Results: 50 patients were recruited during the study. The $100 \%$ of them were women. The mean age was 47 years old (DS+-8.5), while the mean time of evolution of FM was 6 years. 29 patients reported xerostomia of which 4 presented positive sialometry. No positive sialometry was found in the group that did not referred xerostomia. Smoking was more prevalent in patients with FM who did not 